\title{
Engraftment of Reprogrammed Human Bile Duct Cells Transiently Rescues Diabetes in Mice
}

\author{
Anannya Banga ${ }^{1,3 *}$, James Dutton ${ }^{1}$, Margaret Mysz ${ }^{2}$, Beverly Norris ${ }^{2}$, Craig Flory ${ }^{2}$, Brenda Ogle ${ }^{3}$, Jakub Tolar ${ }^{1}$ and Robert Schumacher ${ }^{2}$ \\ ${ }^{1}$ Stem Cell Institute, University of Minnesota, Minneapolis, USA \\ ${ }^{2}$ Center of Translational Medicine, University of Minnesota, Minneapolis, USA \\ ${ }^{3}$ Department of Biomedical Engineering, University of Minnesota, Minneapolis, USA
}

\begin{abstract}
Differentiation of adult stem/progenitor cells into functional beta cells to provide a successful autologous cell therapy for Type 1 diabetes patients has not yet been achieved. Progenitor cells in the adult pancreas or liver have been considered potential sources of endocrine beta cells based on their ability to repopulate the organ following injury. Here we describe the isolation and reprogramming of a lineage-committed progenitor population of cells in the human bile duct towards a beta cell fate. These cells, which possess SOX9 as a marker, were able to manifest beta cell characteristics upon ectopic expression of pancreatic transcription factors. The beta cells derived from SOX9+ progenitor cells were also able to ameliorate high blood glucose in diabetic mice. The insulin+ islet-like clusters which developed from this progenitor cell type demonstrate the potential of this approach to generate functional, autologous beta cells.
\end{abstract}

Keywords: Reprograming; Beta cell; Diabetes; Bile duct; Stem cells

\section{Introduction}

The ability to restore functioning islet cells to treat diabetes has long been a goal of regenerative medicine technologies. The generation of functional, patient-specific, insulin-producing beta cells is the favored approach for restoring the Type 1 diabetic pancreas with operational islets. Many methods have been proposed to generate beta cells in culture from different stem cell sources. Generating the actual islets in a dish, however, is still unachievable due to insufficient knowledge of the intricacies of islet differentiation. Among the most recent advances, Pagliuca, et al. [1] showed that differentiating hiPSCs for an extended period of time with KGF and SANT1 generated an unprecedented amount of NKX6.1/C-peptide+ beta cells, which were able to secret adequate levels of insulin in response to changing levels of glucose. The hope has been to identify one or more lineage-committed pancreatic precursor populations with wide availability and an appropriate epigenetic landscape that can be reprogrammed to functional islet beta cells.

An early attempt to use non-beta cells as sources to generate beta cells was reported by Wang, $\mathrm{RN}$ et al. [2]. This study demonstrated that progenitor cells within the ducts are one of the sources of cells in the regenerative process following Pancreatic Duct Ligation (PDL) and that these cells can be differentiated into islet cells. Duct cells in the adult pancreas have long been the assumed source of beta cells. Thus, based on their ability to repopulate the organ following injury, adult stem cells are now considered a viable alternative source of new beta cells [3].

Various other groups have reported that pancreatic ductal cells can give rise to pancreatic endocrine cell types following PDL in adult mice using lineage tracing experiments $[4,5]$. Other studies by Lola Reid's group have identified several multipotent stem/progenitor cells of endodermal origin within peribiliary glands of the extrahepatic biliary tree that can give rise to hepatocytes, cholangiocytes, and pancreatic islets in vivo as well as in vitro culture conditions [6-8]. In adults, a continuous zone of cells expressing SOX9 are present throughout the pancreatic ductal tree as well as within the entire biliary system comprising of the intrahepatic and extra hepatic region, but their contribution towards maintenance of homeostasis of adult liver and pancreatic endocrine cells are controversial $[9,10]$.
Our own work has shown that the SOX9+ cells within the bile duct possess the potential to be reprogrammed into a beta like state in vivo in mice [11]. Another recent study has reported that SOX9+ pancreatic ductal cells in adult mice can differentiate into insulin-producing beta cells under moderate hyperglycemia combined with long-term administration of low-dose gastrin and epidermal growth factor [12].

In our current study, based on the outcome of our previous in vivo findings, we describe an attempt to differentiate the lineage-committed progenitors present within human bile ducts towards a beta cell fate by ectopic expression of the pancreatic transcription factors Pdx1, Ngn3 and MafA. The present study has important repercussions for future strategies aimed at generating high numbers of functional autologous beta cells, which may help to restore normoglycemia in patients suffering from diabetes.

\section{Materials and Methods}

\section{Isolation of bile duct progenitor cells from human liver samples}

Samples of human liver tissue were obtained from the Liver Tissue Distribution System (LTCDS), a National Institutes of Health (NIH) service contract to provide human liver tissue from regional centers for distribution to scientific investigators throughout the United States. Each piece of human primary liver tissue obtained from LTCDS was minced well and digested with a buffer consisting of $1.67 \mathrm{mg} / \mathrm{ml}$ Collagenase Type II (Worthington), $1.33 \mathrm{mg} / \mathrm{ml}$ hyaluronidase (Sigma Aldrich) and $1.34 \mathrm{U} / \mathrm{ml}$ Dispase (BD Biosciences), dissolved in DMEM/ F12 (Gibco, CA), and supplemented with $0.5 \mathrm{mM}$ EGTA, $5 \mathrm{mM}$

*Corresponding author: Anannya Banga, Department of Biomedical Engineering, University of Minnesota, Minneapolis, USA, Tel: 6519003486; Fax: 6126242436; E-mail: banga007@umn.edu

Received June 18, 2018; Accepted July 19, 2018; Published July 23, 2018

Citation: Banga A, Dutton J, Mysz M, Norris B, Flory C, et al. (2018) Engraftment of Reprogrammed Human Bile Duct Cells Transiently Rescues Diabetes in Mice. Stem Cell Res Ther 8: 432. doi: 10.4172/2157-7633.1000432

Copyright: $\odot 2018$ Banga A, et al. This is an open-access article distributed under the terms of the Creative Commons Attribution License, which permits unrestricted use, distribution, and reproduction in any medium, provided the original author and source are credited. 
glucose, $5 \mathrm{mM} \mathrm{KCl}$, and $10 \mathrm{mM}$ HEPES, $\mathrm{pH}$ 7.4. The suspension was then incubated in a $37^{\circ} \mathrm{C}$ water bath for about $45 \mathrm{~min}$ with intermittent shaking. The large hepatocytes were sedimented by centrifuging at $10 \mathrm{~g}$ for $3 \mathrm{~min}$. The supernatant was then spun at $100 \mathrm{~g}$ for $5 \mathrm{~min}$. followed by washing of the pellet with medium containing $10 \%$ serum followed by another spin at $100 \mathrm{~g}$ for $5 \mathrm{~min}$. Nonparenchymal Cells (NPCs) including bile duct progenitor cells, were included in the pellets.

\section{Culture and propagation of bile duct progenitor cells in suspension and attachment cultures}

The bile duct progenitor cells expressing SOX9 were then plated in ultra-low attachment plates (Corning) in DMEM/F12 (Invitrogen) media containing $3 \%$ heat inactivated FBS, supplemented with 1XNEAA, and $20 \mathrm{ng} / \mathrm{ml}$ EGF (R\&D Systems) for suspension culture. These cells formed small clusters of cells in suspension culture which were then placed in 6 well plates after 7 days and expanded in adherent culture in the same medium for 2-3 weeks with occasional splitting.

\section{Transduction of bile duct progenitor (SOX9+) cells with Ad-} PNM

An adeno viral vector (Ad-PNM), carrying mouse Pdx1, Ngn3 and MafA in a single polycistronic unit, separated by $2 \mathrm{~A}$ sequences, was prepared as described previously [13]. The SOX9+ cell clusters were trypsinised to make a single cell suspension. They were then transduced with Ad-PNM at a $100 \mathrm{MOI}$ (multiplicity of infection) in the ultra-low attachment plate. The cells were then incubated in a $37^{\circ} \mathrm{C}$ incubator for 48-72 hrs. The infection was done in absence of serum in DMEM/F12 medium. The medium was changed after two days and the cells were cultured in suspension culture for another 7-10 days in the culture medium previously described. They were next plated onto 6 well plates with or without hydrogel (ESI-Bio) coating according to manufacturer's instructions and grown for 2-3 weeks in adherent culture for maturation.

Preliminary trials showed that a MOI of 25-100 gave maximum insulin+ cells with minimum toxicity, so this range was adopted as the standard for the study. The Ad-PNM infection efficiency was obtained by counting all the cells in three fields of vision and taking an average percentage of the cell population showing nuclear PDX1 immunostaining.

Transplantation of bile duct progenitor cell derived insulin+ beta like cells under the kidney capsule of diabetic mice

The NOD-SCID (Prkdc ${ }^{\text {scid }}$ ) mice from Jackson laboratories (three experimental and two controls) were initially made diabetic by injecting $120 \mathrm{mg} / \mathrm{Kg}$ of Streptozotocin (STZ) intraperitoneally for approximately 2 weeks. The mice were monitored until they reached a blood glucose level of $400 \mathrm{mg} / \mathrm{dl}$. The clusters of insulin+ expressing cells were slightly trypsinized to detach from the plate without making them into a single cell suspension. Approximately 3-4 insulin+ clusters from each 6 well plate were injected into each of the three mice. The cells (after centrifugation) were mixed with fibrinogen-thrombin in 1:2 ratio in order to make a graft, each of which was slid under the kidney capsules of diabetic mice. The blood glucose level in these mice was monitored every other day following transplantation of the reprogrammed SOX9+ cells. The graft was excised 7 days after transplantation and analyzed for insulin expression by immune histochemical analysis.

\section{Immune staining of the insulin+ clusters}

The differentiated SOX9+ cell derived cultures were fixed 3-4 weeks after Ad-PNM administration with buffered formalin for 15 min (1:10 dilution Protocol, Fisher Scientific Company LLC). After washing, cells were permeabilized with $0.1 \%$ TritonX-100 in PBS for $10 \mathrm{~min}$. They were then blocked with PBS $+0.1 \%$ TritonX-100 and $10 \%$ normal goat serum (Jackson ImmunoResearch) for $1 \mathrm{hr}$, and then samples were incubated with primary antibodies overnight.

Primary antibodies used were as follows: rabbit anti-PDX1 (1:1000 dilution; Millipore); rabbit anti-MAFA (1:100 dilution; Santa Cruz Biotechnologies); guinea-pig anti-insulin (1:200 dilution; Abcam); mouse anti-Ecad (1:100 dilution; BD Biosciences); mouse anti-epithelial cell adhesion molecule (EpCAM; 1:100 dilution; Santa Cruz Biotechnology), anti-SOX-9 rabbit polyclonal (1:1000 dilution; Millipore). Secondary antibodies (Invitrogen), used were as follows: alexa fluor 488 goat anti-rabbit IgG; alexa fluor 488 rabbit anti-mouse; alexa fluor 594 goat anti-guinea pig IgG; alexa fluor 647 goat antiguinea pig IgG; alexa fluor 555 goat anti-rabbit IgG. All secondary antibodies were used in 1:500 dilutions. Images were taken on a Leica DMI6000 B inverted microscope by a Retiga2000 camera using iPLab software.

\section{Quantitation of insulin secretion}

Seven days after Ad-PNM transduction or after 14 days of culture on hydrogel or collagen plates, insulin + clusters plated in 6 well plates were incubated in Krebs-Ringer Buffer (KRB) for $30 \mathrm{~min}$ at $37^{\circ} \mathrm{C}$ to release any adsorbed insulin. Then cells were incubated in KRB supplemented with $2.8 \mathrm{mM}$ glucose or $20 \mathrm{mM}$ glucose for $45 \mathrm{~min}$ at $37^{\circ} \mathrm{C}$. Cells without Ad-PNM transduction were used as controls. The medium was collected and concentrated by Amicon Ultra-15 centrifugal filter units (Millipore). The supernatant was then collected for measurement of total insulin content. The concentrations of insulin in the medium were measured using an Ultrasensitive Human Insulin ELISA kit (ALPCO), according to the manufacturer's protocol.

\section{Quantitative Reverse Transcription - Polymerase Chain Reaction (qRT-PCR)}

Total RNA from the insulin + cell cultures were isolated using TRI reagent (Sigma-Aldrich), according to the manufacturer's protocol. Extracted RNA samples were incubated at $37^{\circ} \mathrm{C}$ with DNase enzyme (Promega) for $45 \mathrm{~min}, 3$ times, to achieve a complete elimination of potential residual genomic DNA. Then $2 \mu \mathrm{g}$ RNA was used to synthesize cDNA by SuperScript III Reverse Transcriptase, random primers, dNTP (10 mM) and RNaseOUT Recombinant Ribonuclease Inhibitor (Invitrogen). The PCR program was an initial denaturation at $95^{\circ} \mathrm{C}$ for $30 \mathrm{sec}$, followed by 40 cycles of amplification which includes denaturation at $95^{\circ} \mathrm{C}$ for $5 \mathrm{sec}$ and then annealing at $60^{\circ} \mathrm{C}$ for $20 \mathrm{sec}$ followed by extension at $72^{\circ} \mathrm{C}$ for $1 \mathrm{~min}$. The gene expression profiles were compared by qRTPCR for Glyceraldehyde-3phosphate dehydrogenase (Gapdh), Ins1, endogenous Pdx1, Glucagon (Gcg), Somatostatin (Sst), Pancreatic polypeptide (Ppy), paired box 4 (Pax4), regulatory factor X 6 (Rfx6), potassium inwardly-rectifying channel subfamily J member 11 (Kcnj11), SRY-box containing gene 9 (SOX9), Pdx1, Ngn3, aristaless related homeobox (Arx), NK2 homeobox 2 (Nkx2.2), Amylase 2a1 (Amy2a1), Ngn3, Nkx6.1, ATP-binding cassette transporter sub-family $\mathrm{C}$ member 8 (Abcc8), and Isl1. Primer sequences are available upon request. The expression levels of the genes of interest were expressed relative to transcripts of the gene for the ubiquitous enzyme Glyceraldehyde-3-Phosphate Dehydrogenase (GAPDH), which was normalized to zero.

\section{Results}

Initially, we tried to determine the presence of a SOX9 progenitor 
zone in the bile ducts of SOX9CreER/mTmG mice (Supplementary Figure 1A). The isolation and culture of SOX9+ progenitor cells from the liver bile ducts was standardized by using the mouse strain, SOX9CreERT2/mT/mG. In these mice, Tamoxifen injection at E14.5 enabled us to label the SOX9 cells with GFP [11]. After digestion of liver tissue with collagenase followed by a differential centrifugation procedure as described in materials and methods, we were able to separate the SOX9+ cells (green) from the large volume of hepatocytes (non-green) (Supplementary Figure 1B). Moreover, in the designated medium only the SOX9+ cells were able to attach and grow. In addition, the presence of green fluorescence in these SOX9 cells allowed us to eliminate the other cells in culture without losing the SOX9 cells in the cellular debris. We then sorted the GFP+ cells, which were positive for SOX9 as well, and we developed culture conditions for both adherent and suspension culture of the cells. In suspension culture the SOX9+ cells formed clusters that were either hand-picked or flow sorted (Supplementary Figure 1C).

\section{Isolation and characterization of SOX9+ bile duct progenitor cells from human liver}

Characterization of the human liver cryo-sections showed expression of SOX9, EpCaM, ECAD and CK19 in the bile ducts (Figure 1). Initially we tried to isolate the SOX9+ cells from the human liver by sorting for EpCaM+ cells (data not shown), but later we resorted to a differential centrifugation procedure. The hepatocytes, having a higher Svedberg unit or sedimentation coefficient, were sedimented upon centrifugation at $10 \mathrm{~g}$. The supernatant containing the bile duct cells and other NPCs were sedimented at a higher speed of $100 \mathrm{~g}$. Re-suspension of the cell pellet and plating in 3\% FBS medium in suspension culture resulted in formation of ball like clusters or colonies. These clusters when allowed to adhere were found to attach and expand, leaving other cells, including any hepatocytes, unattached and were thus eliminated from the culture during subsequent steps of culture (Figure 2). The cells were found to be epithelial in nature and staining these clusters with SOX9 antibody showed the presence of SOX9+ cells (Figure 2) as well as other ductal markers such as ECAD (Figure 2). Thus we confirmed that the human biliary epithelial cells were able to expand and grow in culture. These bile duct progenitor cells were found to express SOX9 for an extended period of time. The cells were found to be robust and did not require everyday feeding.

\section{Reprograming potential of the SOX9+ bile duct progenitor cells into beta like cells}

We used the same Ad-PNM virus to evaluate if overexpression of the three pancreatic transcription factors can reprogram the SOX9+ cells bile duct progenitor cells isolated from human liver [13]. Transduction of the cells was noticed as early as three days following infection with Ad-PNM. Moreover, it was observed that though most of the cells expressed Pdx1, insulin expression was limited to only the SOX9+ cells concentrated in the middle region as opposed to the cells spread out near the edges of the culture. Immuno-histochemical staining with insulin and C-peptide antibody revealed that these cells were able to acquire beta cell characteristics (Figure 3 ) and thus were defined as the insulin+ clusters. The important beta cell marker NKX6.1 was found to be co-expressed along with insulin and C-peptide, thereby confirming the mature beta cell phenotype of the SOX9 derived clusters (Figure 3).

To test the potential of the bile duct progenitor cells to reprogram into insulin + cells, we performed q-PCR analysis. The qPCR analysis demonstrated the induced expression of multiple beta cell gene transcripts in addition to SOX17, FOXA2, SOX9 and PDX1 in AdPNM

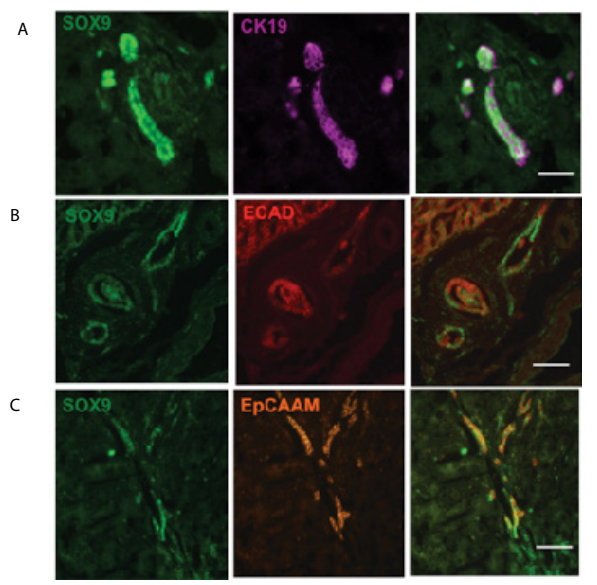

Figure 1: Characterization of human liver tissue sample shows SOX9+ cells within the small bile ducts of the liver express ductal markers. Immunohistochemical staining of micro sections of human liver with SOX9 antibody followed by co-staining with ductal markers such as A) CK19, B) ECAD and C) EpCAM antibody. Scale bars are $100 \mu \mathrm{m}$.

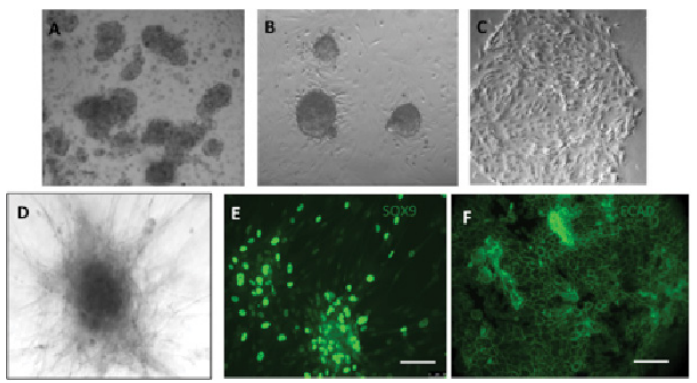

Figure 2: Isolation and in vitro expansion of human bile duct cells in culture samples in adherent culture system after digestion: A) Bile duct cells in ultralow attachment plates clump together and form clusters; B) The clusters attach to the plate within 7 days; C) The clusters expand on plastic by adherence; D) On collagen, the clusters form duct like structures; E) The clusters are positive for SOX9 when stained with anti-human SOX9 antibody; F) The clusters are positive for ECAD and are able to expand on plastic surface. Scale bars are $100 \mu \mathrm{m}$.

treated SOX9+ cells when compared with non-treated cells (Figure 4A). In contrast, Amy2a, Arx, SST, and GCG were not induced.

Functional analysis of the human SOX9+ derived insulin+ cells

The insulin+ cells derived from human SOX9 cells were analyzed for insulin secretion upon stimulation with $2 \mathrm{mM}$ and $20 \mathrm{mM}$ glucose in the KRB buffer. Insulin + cells when plated on plastic were found to secrete $1.5 \mathrm{ng} / \mathrm{ml}$ of insulin. An improved level of insulin secretion up to $2.57 \mathrm{ng} / \mathrm{ml}$ was noticed when the insulin+ clusters were cultured on collagen and hydrogel (Figure 4B). Almost a two-fold increase in insulin secretion was noticed when these cells were cultured in hydrogel and collagen coated 6 well plates for two weeks.

\section{Re-establishment of beta cell functional properties with} Reprogrammed SOX9+ cells of bile duct

In order to examine the ability of the insulin+ beta cells derived from the SOX9+ progenitor cells of human liver samples to affect blood sugar levels, they were transplanted into diabetic NOD-SCID $\left(\right.$ Prkdc $\left.^{\text {scid }}\right)$, mice. Approximately twenty SOX9 derived insulin+ clusters were transplanted into each of the mice. The clusters were 
mixed with fibrinogen and thrombin to generate a patch that was then slid under the kidney capsule. The reprogrammed SOX9+ cells were found to reverse diabetes in these mice within the first seven days of transplantation (Figure 5A). On the other hand, control animals which did not receive any implanted cells continued to show persistent hyperglycemia. A glucose challenge of the mice with grafts showed that they were able to clear glucose consistently, though at a slower pace compared to the control mice without diabetes, indicating the glucose responsive nature of the differentiated SOX9 derived human beta cells (Figure 5C). Engraftment of the reprogrammed insulin+ human cells was confirmed by immunofluorescence staining with anti-Stem 121 antibody (Figure 5B). Stem 121 antibody, which is known to react specifically with a cytoplasmic protein of human cells, was found to stain these sporadic patches of insulin + cells within the mouse kidney capsule. Thus, it was confirmed that insulin+ cells in the graft were derived from the in vitro differentiated progenitor cells derived from the human bile duct.

Therefore, these preliminary results with the SOX9 derived cells provides convincing evidence in support of the use of these progenitor cells as a potential source for generating autologous beta cells.

\section{Discussion}

The discovery of a stem/progenitor cell type that can be routinely used as a source for making autologous beta cells has been elusive. Apart from the ESCs or iPSCs, it is adult primary stem/progenitor cells that also have the potential to be reprogrammed to beta cells. We observed that SOX9+ cells are stable and expandable, and hence hold great promise for autologous beta cell replacement therapy for Type 1 diabetic patients.

Around embryonic day (E) 8.5, murine pancreatic endoderm expresses critical transcription factors, such as pancreas duodenal homeobox (Pdx) 1 and SOX9.
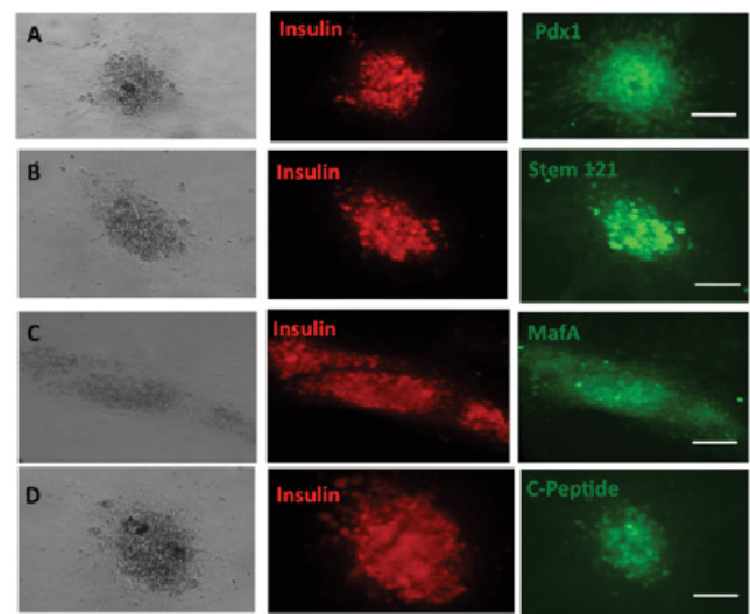

E
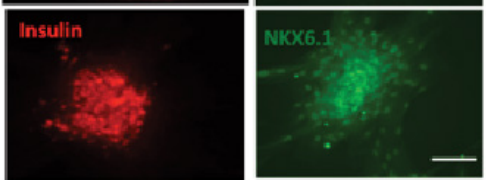

Figure 3: Characterization of reprogrammed SOX9+ cells derived from bile ducts; Human SOX9+ cells express human beta cell protein markers upon ectopic expression of Ad-PNM. Representative immune-histochemical staining of reprogrammed SOX9+ cells expressing insulin (red) and costained in green for beta cell markers, 14 days after Ad-PNM infection A) Pdx1; B) Human antigen Stem 121; C) MafA; D) C-peptide; E) Nkx 6.1. Scale bars are $100 \mu \mathrm{m}$
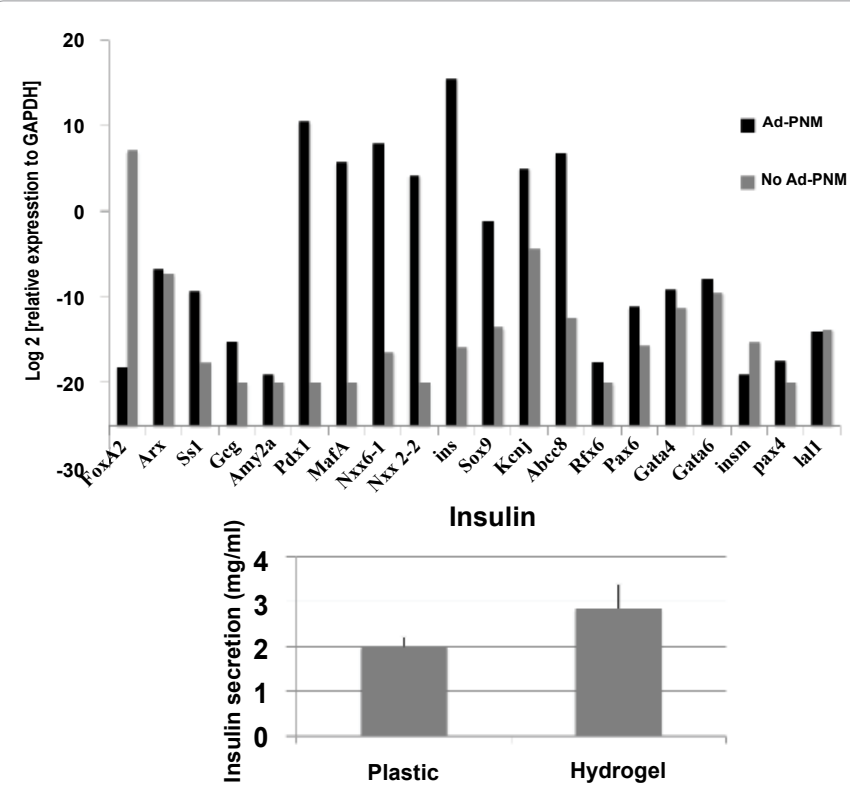

Figure 4: Characterization of reprogrammed SOX9+ cells derived from bile ducts; A) Gene expression analysis by real time qRT-PCR for beta cells markers in reprogrammed bile duct cells. Ct values were normalized to Gapdh gene expression within the same cDNA sample. Results are presented as fold increase based on Gapdh gene expression and the values on the $y$ axis represent $\log 2$ multiples of the Gapdh value, which is represented by 0 . The data are means of three independent experiments on livers collected 12 weeks after Ad-PNM administration; B) Insulin+ cells generated from bile duct derived SOX9+ cells secrete insulin differentially on plastic and hydrogel surfaces. ELISA measurements of human insulin from comparable number of clusters were cultured on plastic and hydrogel for 7 days. Data represent mean \pm SD from three different experiments on livers collected 12 weeks after Ad-PNM administration.
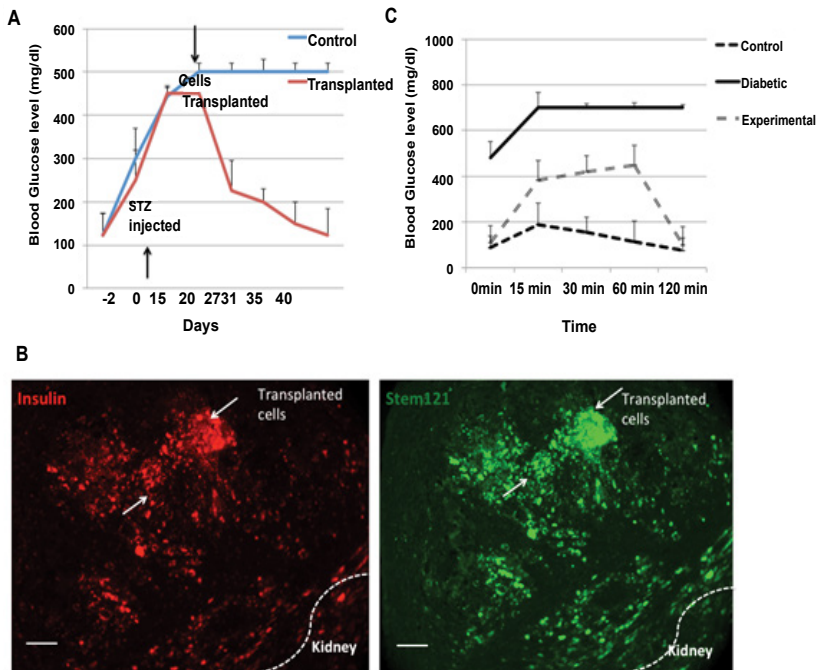

Figure 5: Insulin+ beta cell clusters derived from SOX9+ cells ameliorate hyperglycemia in NOD-SCID (Prkdc scid) mice. A) Blood glucose levels on different days following transplantation of the insulin+ clusters. The two arrow heads show the day on which Streptozotocin was injected and the day of transplantation of the insulin+ clusters. B) Representative Immunohistochemical analysis of the grafts within the kidney capsule with Insulin and Stem 121 antibody, ten days after transplantation. The two arrow heads show the insulin expressing cells which are also positive for Stem 121 antigen C) Mice were fasted for 16 hours, and then blood glucose was measured at different time points following a glucose injection of mice, 14 days posttransplantation. Scale bars are $100 \mu \mathrm{m}$. 
These Pdx1+ and SOX9+ ductal cells are multi-potential and possess the capability to form all of the three lineages in the adult pancreas between E8.5 and E12.5 [14,15]. On the other hand, after E12.5, the lineage potential of the ductal epithelium becomes restricted $[14,15]$ and are differentiated into endocrine cells only in presence of neurogenin $3[16,17]$.

We propose to use SOX9+ ductal cells of the pancreatic duct as well as the bile duct as sources for making our future autologous beta cells. This proposal is based on our preliminary in vitro differentiation of human SOX9+ cells of the bile duct as well as our in vivo study [11], which have given us the basis for undertaking this initiative. In our former study, we were able to show that the three pancreatic transcription factors, Pdx1, Ngn3 and MafA are sufficient to instruct differentiation of the SOX9+ human bile duct progenitor cells towards a beta cell fate which are functional when transplanted into diabetic mice.

A recent similar study has shown that pancreatic SOX9+ ductal cells in adult mice can be differentiated into insulin-producing beta cells and can contribute to amelioration of diabetes in immune competent mice in the presence of moderate hyperglycemia [12].

Numerous studies have described tripotent progenitor cells residing in the adult murine pancreas, and these "Pancreatic Colony-Forming Units" (PCFUs) are capable of multi-lineage differentiation and robust self-renewal in vitro [18-20]. Several other studies have demonstrated that the pancreatic ductal cells of adult mice are clonogenic and can give rise to insulin-producing beta cells under certain in vitro culture conditions [19-22] Huch, et al. [23] have shown that Lgr5+ adult stem/ progenitor cells can undergo unlimited expansion in culture upon Wnt activation and could be differentiated into exocrine or endocrine cells with appropriate differentiation cues.

Contrary to these findings, a number of studies have been performed by Solar, et al. [24] Kopp, et al. [25] and Furuyama, et al. [10] using a lineage-tracing models with different promoters to delineate the fate of these ductal cells within bile and pancreatic ducts. Solar, et al. [24] reported that ductal epithelial cells do not significantly contribute to beta cells in neonates, PDL-treated adult mice, or Alloxan-induced diabetic adult mice treated for 1 week with gastrin or EGF. Kopp, et al. [25], using a lineage-tracing model with a SRY (sex-determining region Y)-box 9 (SOX9) promoter, also showed that SOX9+ ductal cells did not give rise to beta cells postnatally after beta cell ablation or after PDL. Similarly, Furuyama, et al. [10], reported that SOX9+ pancreatic ductal cells were not able to give rise to beta cells in PDL-treated adult mice or STZ-induced diabetic mice.

In this study, we assessed the competence of SOX9+ human bile duct progenitor cells to differentiate into beta cells using the three transcription factors. Pancreatic transcription factors are highly conserved in vertebrates, and thus our mouse transcription factors were able to elicit the human beta cell gene expression portfolio within the human bile duct cells. These SOX9+ cells as committed precursors were easily coaxed into endocrine cell fate with ectopic expression of pancreatic transcription factors, possibly due to the close relationship and the epigenetic similarity of the endocrine cell types.

It is significant to note that these SOX9+ cells had the tendency to form clusters or colonies both in suspension culture as well as in adherent culture despite dispersing them to into single cell suspension, presumably due to their epithelial characteristics. These clusters were able to expand in culture without losing either the SOX9 marker or their ductal characteristics (Figure 2 (D-E)). When plated on plastic, these cells formed a defined island as noted in Figure 3. These clusters were found to exclusively stain for insulin and other beta cell markers, and thus were named insulin+ clusters (Figure 3), while on hydrogel and collagen they were found to form duct like structures (Figure 2D). Moreover, a co-expression of insulin along with C-peptide and Nkx6-1 indicated their true beta cell characteristics, which further signified that the pancreatic transcription factors were potent enough to induce/activate ductal to endocrine reprogramming (Figure 3). It is known from conditional knock out studies of NKX6-1 that expression of NKX6-1 is a key contributing factor for beta cell function [26]. Moreover, differentiation protocols that expressed higher levels of NKX6-1 led to better outcomes in transplantation experiments [27]. Further, in-depth analysis may be required to reveal which additional genes and epigenetic mechanisms regulating the maturation process of pancreatic beta cells might be in play.

We presume that the SOX9+ cells in culture responded to the inductive signals of the pancreatic transcription factors by activating the beta cell specification differentiation program and elicited the expression of beta cell specific markers. Similarly, Ghazalli, et al. [28] showed that SOX9 expressing cells from neonatal pancreas enriched in CD133 can form colonies and differentiate into beta like cells in an artificial ECM matrix. However, we understand that long term studies and a mechanistic understanding of such changes are necessary in order to use these cells as an autologous cellular source for making beta cells.

An increase in human insulin secretion was observed when these cells were cultured on hydrogel and collagen, which indicated that specific matrices might be required to provide the essential cues and optimum conditions towards functionality of the SOX9 derived insulin+ clusters (Figure 4B). This is similar to reports in other studies $[29,30]$, where hydrogels, supplemented with ECM molecules like collagen, were shown to enhance the viability and insulin secretion of encapsulated islets or differentiated embryonic stem cells. Such 3D cultures have been known to produce 3.5 times more GlucoseStimulated Insulin Secretion (GSIS) compared to 2D culture. On the other hand, Lozoya, et al. [31] showed that Hyaluronic Acid (HA) is a key component in the matrix chemistry of the hepatic stem cell niche and can induce transition of hepatic stem cell colonies towards stable heterogeneous populations of hepatic progenitors.

When transplanted into immune deficient mice, these SOX9+ derived insulin+ cells were able to ameliorate diabetes in the mice within the first two weeks after transplant and were also able to respond to a glucose challenge (Figure 5C). This was attributed to the presence of insulin+ clusters observed in the kidney capsule after two weeks post-transplantation. The duration required to restore normal glucose levels may be due to the small number of insulin+ cells transplanted. These cells did not require a prolonged period of quiescence before they could secrete insulin and respond to glucose, thereby increasing their potential for clinical applications. However, we did not perform a long term study to validate the persistence of this response to glucose.

Thus, we believe, based upon results from both in vitro and in vivo studies, that these SOX9+ cells residing in the bile duct can be considered as an adult pancreatic precursor with potential for pancreatic regeneration upon inducing them with certain pancreatic specific stimulators like hyperglycemia as noticed by Zhang, et al. [12].

The current approach could be a feasible alternative to a commonly used iPSC approach for generating autologous beta cells to advance the current field of cell therapy. The ability to reprogram these biliary progenitor cells offers an unprecedented opportunity to use these cells 
as a source for making autologous beta cells in a dish and thereby provides a promising cell therapy.

In summary, our study demonstrates an effective reprogramming of human bile duct progenitor cells into insulin+ beta like cells. Significantly, our in vitro-differentiated beta-like cells exhibit a functional beta-cell phenotype as judged by their ability to secrete insulin in response to physiological levels of glucose, and by their coexpression of critical beta-cell transcription factors. Though much work remains to be done, these cells could provide a source of beta cells for controlled insulin secretion in response to fluctuating physiological demands. This represents a step towards clinical translation by reprogramming autologous progenitor cells of the body.

\section{Acknowledgement}

We are thankful to Dr. Jonathan Slack for his invaluable comments and edits along with useful advice. We further extend our thanks to Dr. Robert Schumache and his group at CTSI for their meticulous reading through the paper and their critical comments. We are also thankful to Dr. Brenda Ogle and Dr. Jakub Tolar for their support in completing this manuscript. This study was supported by the Clinical and Translational Science Institute of University of Minnesota, NIH grant \# 5R01-DK080747-04, and the Stem Cell Institute of the University of Minnesota.

\section{References}

1. Pagliuca FW, Millman JR, Gürtler M, Segel M, Van Dervort A, et al. (2014) Generation of functional human pancreatic $\beta$ cells in vitro. Cell 159: 428-439. [PubMed]

2. Wang RN, Klöppel G, Bouwens L (1995) Duct- to islet-cell differentiation and islet growth in the pancreas of duct-ligated adult rats. Diabetologia 38: 14051411. [PubMed]

3. Bonner-Weir S, Toschi E, Inada A, Reitz P, Fonseca SY, et al. (2004) The pancreatic ductal epithelium serves as a potential pool of progenitor cells. Pediatr Diabetes 5: 16-22. [PubMed]

4. Inada A, Nienaber C, Katsuta H, Fujitani Y, Levine J, et al. (2008) Carbonic anhydrase II-positive pancreatic cells are progenitors for both endocrine and exocrine pancreas after birth. Proc Natl Acad Sci USA 105: 19915-19919. [PubMed]

5. Xu X, D'Hoker J, Stangé G, Bonné S, De Leu N, et al. (2008) $\beta$ cells can be generated from endogenous progenitors in injured adult mouse pancreas. Cell 132: 197-207. [PubMed]

6. Cardinale V, Wang Y, Carpino G, Cui CB, Gatto M, et al. (2011) Multipoten stem/progenitor cells in human biliary tree give rise to hepatocytes, cholangiocytes, and pancreatic islets. Hepatology 54: 2159-2172. [PubMed]

7. Cardinale V, Wang Y, Carpino G, Mendel G, Alpini G, et al. (2012) The biliary tree--a reservoir of multipotent stem cells. Nat Rev Gastroenterol Hepatol 9: 231-240. [PubMed]

8. Carpino G, Cardinale V, Onori P, Franchitto A, Berloco PB, et al. (2012) Biliary tree stem/progenitor cells in glands of extrahepatic and intraheptic bile ducts an anatomical in situ study yielding evidence of maturational lineages. J Anat 220:186-199. [PubMed]

9. Kawaguchi $Y$ (2013) Sox9 and programming of liver and pancreatic progenitors. J Clin Invest 123: 1881-1886. [PubMed]

10. Furuyama K1, Kawaguchi Y, Akiyama H, Horiguchi M, Kodama S, et al. (2011) Continuous cell supply from a Sox9-expressing progenitor zone in adult liver, exocrine pancreas and intestine. Nat Genet 43: 34-41. [PubMed]

11. Banga A, Akinci E, Greder LV, Dutton JR, Slack JM (2012) In vivo reprogramming of Sox9+ cells in the liver to insulin-secreting ducts. Proc Natl Acad Sci USA 109: 15336-15341. [PubMed]

12. Zhang M, Lin Q, Qi T, Wang T, Chen CC, et al. (2016) Growth factors and medium hyperglycemia induce Sox9+ ductal cell differentiation into $\beta$ cells in mice with reversal of diabetes. Proc Natl Acad Sci USA 113: 650-655. [PubMed]

13. Akinci E, Banga A, Greder LV, Dutton JR, Slack JM (2012) Reprogramming of pancreatic exocrine cells towards a beta $(\beta)$ cell character using Pdx1, Ngn3 and MafA. Biochem J 442: 539-550. [PubMed]

14. Gu G, Dubauskaite J, Melton DA (2002) Direct evidence for the pancreatic lineage: NGN3+ cells are islet progenitors and are distinct from duct progenitors. Development 129: 2447-2457. [PubMed]

15. Kopp JL, Dubois CL, Schaffer AE, Hao E, Shih HP, et al. (2011) Sox9+ ducta cells are multipotent progenitors throughout development but do not produce new endocrine cells in the normal or injured adult pancreas. Development 138 : 653-665. [PubMed]

16. Apelqvist A, Li H, Sommer L, Beatus P, Anderson DJ, et al. (1999) Notch signalling controls pancreatic cell differentiation. Nature 400: 877-881. [PubMed]

17. Gradwohl G, Dierich A, LeMeur M, Guillemot $F(2000)$ neurogenin3 is required for the development of the four endocrine cell lineages of the pancreas. Proc Natl Acad Sci USA 97: 1607-1611. [PubMed]

18. Fu X, Jin L, Wang $X$, Luo A, Hu J, et al. (2013) MicroRNA-26a targets ten eleven translocation enzymes and is regulated during pancreatic cell differentiation. Proc Natl Acad Sci 110: 17892-17897. [PubMed]

19. Jin L, Feng T, Shih HP, Zerda R, Luo A, et al. (2013) Colony-forming cells in the adult mouse pancreas are expandable in Matrigel and form endocrine/ acinar colonies in laminin hydrogel. Proc Natl Acad Sci USA 110: 3907-3912. [PubMed]

20. Jin L, Feng $T$, Zerda $R$, Chen CC, Riggs $A D$, et al. (2014) In vitro multi lineage differentiation and self-renewal of single pancreatic colony-forming cells from adult C57BL/6 mice. Stem Cells Dev 23: 899-909. [PubMed]

21. Bonner-Weir S, Taneja M, Weir GC, Tatarkiewicz K, Song KH, et al. (2000) In vitro cultivation of human islets from expanded ductal tissue. Proc Natl Acad Sci 97: 7999-8004. [PubMed]

22. Yamada T, Cavelti-Weder C, Caballero F, Lysy PA, Guo L, et al. (2015) Reprogramming mouse cells with a pancreatic duct pheno- type to insulinproducing $\beta$-like cells. Endocrinology 156: 2029-2038. [PubMed]

23. Huch M, Bonfanti P, Boj SF, Sato T, Loomans CJ, et al. (2013) Unlimited in vitro expansion of adult bi-potent pancreas progenitors through the Lgr5/Rspondin axis. EMBO J 32: 2708-2721. [PubMed]

24. Solar M, Cardalda C, Houbracken I, Martín M, Maestro MA, et al. (2009) Pancreatic exocrine duct cells give rise to insulin-producing beta cells during embryogenesis but not after birth. Dev Cell 17: 849-860. [PubMed]

25. Kopp JL, Dubois CL, Hao E, Thorel F, Herrera PL, et al. (2011) Progenitor cell domains in the developing and adult pancreas. Cell Cycle 10: 1921-1927. [PubMed]

26. Taylor BL, Liu FF, Sander M (2013) Nkx6.1 Is Essential for Maintaining the Functional State of Pancreatic Beta Cells. Cell Rep 4: 1262-1275. [PubMed]

27. Rezania A, Bruin JE, Xu J, Narayan K, Fox JK, et al. (2013) Enrichment of human embryonic stem cell-derived NKX6.1-expressing pancreatic progenitor cells accelerates the maturation of insulin-secreting cells in vivo. Stem Cells 31: 2432-2442. [PubMed]

28. Ghazalli N, Mahdavi A, Feng T, Jin L, Kozlowski MT, et al. (2015) Postnata Pancreas of Mice Contains Tripotent Progenitors Capable of Giving Rise to Duct, Acinar, and Endocrine Cells In Vitro. Stem Cells Dev 24: 1995-2008. [PubMed]

29. Wang $X$, Ye K (2009) Three-dimensional differentiation of embryonic stem cells into islet-like insulin-producing clusters. Tissue Eng Part A 15: 1941 1952. [PubMed]

30. Amer LD, Mahoney MJ, Bryant SJ (2014) Tissue Engineering Approaches to Cell-Based Type 1 Diabetes Therapy. Tissue Eng Part B Rev 20: 455-467. [PubMed]

31. Lozoya OA, Wauthier E, Turner RA, Barbier C, Prestwich GD, et al. (2011) Regulation of hepatic stem/progenitor phenotype by microenvironmen stiffness in hydrogel models of the human liver stem cell niche. Biomaterials 32: 7389-7402. [PubMed]

32. Bruin JE, Rezania A, Xu J, Narayan K, Fox JK, et al. (2013) Maturation and function of human embryonic stem cell-derived pancreatic progenitors in macroencapsulation devices following transplant into mice. Diabetologia 56 : 1987-1998. [PubMed]

33. Chen S, Borowiak M, Fox JL, Maehr R, Osafune K, et al. (2009) A small molecule that directs differentiation of human ESCs into the pancreatic lineage. Nat Chem Biol 5: 258-265. [PubMed]

34. Cheng X, Ying L, Lu L, Galvao AM, Mills JA, et al. (2012) Self-renewing endodermal progenitor lines generated from human pluripotent stem cells. Cell Stem Cell 10: 371-384. [PubMed] 
Citation: Banga A, Dutton J, Mysz M, Norris B, Flory C, et al. (2018) Engraftment of Reprogrammed Human Bile Duct Cells Transiently Rescues Diabetes in Mice. Stem Cell Res Ther 8: 432. doi: 10.4172/2157-7633.1000432

35. D'Amour KA, Bang AG, Eliazer S, Kelly OG, Agulnick AD, et al. (2006) Production of pancreatic hormone-expressing endocrine cells from human embryonic stem cells. Nat Biotechnol 24: 1392-1401. [PubMed]

36. Hrvatin S, O'Donnell CW, Deng F, Millman JR, Pagliuca FW, et al. (2014) Differentiated human stem cells resemble fetal, not adult, b cells. Proc Nat Acad Sci USA 111: 3038-3043. [PubMed]

37. Jiang J, Au M, Lu K, Eshpeter A, Korbutt G, et al. (2007) Generation of insulinproducing islet-like clusters from human embryonic stem cells. Stem Cells 25 : 1940-1953. [PubMed]

38. Kroon E, Martinson LA, Kadoya K, Bang AG, Kelly OG, et al. (2008) Pancreatic endoderm derived from human embryonic stem cells generates glucose- responsive insulin-secreting cells in vivo. Nat Biotechnology 26: 443452. [PubMed]

39. Nostro MC, Sarangi F, Ogawa S, Holtzinger A, Corneo B, et al. (2011) Stage-specific signaling through TGFb family members and WNT regulates patterning and pancreatic specification of human pluripotent stem cells. Development 138: 861-871. [PubMed]

40. Rezania A, Bruin JE, Riedel MJ, Mojibian M, Asadi A, et al. (2012) Maturation of human embryonic stem cell-derived pancreatic progenitors into functional islets capable of treating pre-existing diabetes in mice. Diabetes 61: 20162029. [PubMed]

41. Rezania A, Riedel MJ, Wideman RD, Karanu F, Ao Z, et al. (2011) Production of functional glucagon-secreting alpha-cells from human embryonic stem cells. Diabetes 60: 239-247. [PubMed]

42. Thowfeequ S, Ralphs KL, Yu WY, Slack JM, Tosh D (2007) Betacellulin inhibits amylase and glucagon production and promotes beta cell differentiation in mouse embryonic pancreas. Diabetologia 50: 1688-1697. [PubMed]

43. Xu X, Browning VL, Odorico JS (2011) Activin, BMP and FGF pathways cooperate to promote endoderm and pancreatic lineage cell differentiation from human embryonic stem cells. Mech Dev 128: 412-427. [PubMed] 